\title{
Schelling, Zizek, Baudrillard: la lógica del fantasma
}

\section{Schelling, Zizek, Baudrillard: the spectral logic}

\author{
Ana CARRASCO-CONDE ${ }^{1}$ \\ Universidad Complutense de Madrid / Universidad Politécnica de Madrid, \\ CEI Campus Moncloa
}

Recibido: 07/11/2012

Aceptado: 12/05/2013

\section{Resumen}

El artículo trata de analizar las repercusiones que tiene nuestro tiempo de "sociedad del espectáculo" en la construcción de realidades históricas (Debord). Para ello se analizarán las propuestas de S. Zizek y de J. Baudrillard en torno a lo Real, la realidad y el simulacro, empleando algunos planteamientos de la filosofía de F.W.J. Schelling, mostrando así la relevancia de la filosofía schellinguiana para entender para entender esta construcción.

Palabras clave. Baudrillard, No-Ente, Real, realidad, Schelling, simulación, simulacro, Zizek.

\begin{abstract}
The article tries to analyze the impact of our time of "society of the spectacle" (Debord) in the construction of the historical realities. For this, proposals from S. Zizek and J. Baudrillard about the Real, the reality and the simulacrum will be analyzed, using some approaches to the philosophy of F.W.J. Schelling.
\end{abstract}

\footnotetext{
${ }^{1}$ Research by Ana Carrasco-Conde is also supported by a PICATA Postdoctoral contract of the Moncloa Campus of International Excellence (UCM-UPM).
} 
Keywords. Baudrillard, Not-Being, The Real, reality, Schelling, simulation, simulacrum, Zizek.

La imagen es impactante, casi aterradora. Bertolt Brecht camina por las calles de Berlín. De lejos ve aparecer una columna de tanques soviéticos que avanza, imparable, en dirección a la Stalinalle -el actual boulevard Karl-Marx-Allee-, para aplacar la rebelión de los trabajadores. El ruido es ensordecedor. Los tanques, como gigantes de acero, se mueven pesadamente entre ondeantes banderas con hoces y martillos y entre palabras agolpadas por las consignas del Partido. Al caer la tarde Brecht escribirá en su diario que en ese momento tuvo la tentación por primera vez en su vida de afiliarse de facto al Partido Comunista ${ }^{2}$. Como recuerda Zizek, no se trataba de que Brecht aceptara la "crueldad de la lucha con la esperanza de que llevara a un futuro próspero" sino de que "la fuerza de la violencia como tal era vista y aceptada como una señal de autenticidad"3. Zizek ve por ello en este gesto un ejemplo de lo que Alain Badiou considera la característica principal del siglo XX, que frente a los proyectos e ideales utópicos o "científicos" del XIX, presentaría la pasión por lo Real ${ }^{4}$ o la pasión de lo que podemos denominar "lo verdaderamente real": "el siglo XX -sostiene así Zizek- se ha atrevido a enfrentarse a la cosa en sí, a realizar directamente el añorado Nuevo Orden. El momento verdadero y definitorio del siglo XX es la experiencia directa de lo Real como algo opuesto a la realidad social cotidiana, lo Real en su extrema violencia como precio que hay que pagar por pelar las decepcionantes capas de la realidad"s.

En el fondo esta propuesta de Zizek, que le sirve para entender lacanianamente cómo está conformada la realidad en su diálogo constante con Badiou y con su concepción del acontecimiento ${ }^{6}$, puede ser inscrita en un horizonte mucho más amplio

${ }^{2}$ Cf. Brecht, B.: Diario de trabajo. Vol. 3, Buenos Aires, Nueva Visión, 1977.

${ }^{3}$ Zizek, S.: Bienvenidos al desierto de lo real, Madrid, Akal, 2008, p.11.

${ }^{4}$ Cf. Badiou, A.: Le siècle, París, Editions du Seuil, 2005.

${ }^{5}$ Zizek, S.: Bienvenidos al desierto de lo real, op. cit., p. 11.

${ }^{6}$ Para Badiou, el acontecimiento es un concepto filosófico-político que implica una quiebra o ruptura en el tejido social a través de la cual emerge una verdad no considerada hasta la fecha en el modo simbólico con el que representamos la realidad y que está ligado a una forma de discurso. Pero ninguna simbolización es completa, de forma que se produce una dialéctiva de exceso-defecto que deja ver que en el saber mismo se encuentran zonas de sombra de lo no simbolizado. Esta falta de lo que el saber ignora se pone de manifiesto como síntoma. El acontecimiento entonces lleva a cabo una subversión del orden simbólico establecido para dar lugar a la verdad que se revela en el síntoma. Las repercusiones de este problema son de hondo calado y no sólo en el ámbito de la filosofía de la historia, tema central de este artículo, sino también en el de la filosofía política, puesto que lo que se pone de manifiesto constituye la oportunidad perdida del acto ético y político. De ahí que Zizek vincule, siguiendo a Schelling, la irrupción en la realidad de lo Real, con aquello (el Grund schellinguiano) que, de una forma 
que tiene que ver en último término con la constitución de los procesos históricos y con lo que podemos denominar desde Hegel "el fin de la historia". Efectivamente si el siglo XIX es el siglo de la utopía, lo es porque se percibe que la realidad no es como debería, de ahí el surgimiento de un ideal que coincide con lo que debería ser; hay pues, que cambiar el mundo o, por repetir las conocidas palabras de Marx en su $11^{\mathrm{a}}$ tesis sobre Feuerbach ${ }^{7}$, frente a una filosofía que se ha limitado a interpretar el mundo, es hora ya de transformarlo para la consecución de su plena realización (Verwirklichung), o dicho de otra manera, se ha de hacer efectivo (wirklich) el ideal a través de la acción con el propósito de construir una nueva realidad ${ }^{8}$. Esta construcción tiene unos efectos (Wirkung) en la recepción e interpretación de la historia.

fantasmática, encubre el acto puro de la decisión. Zizek citará a John Sallis que, como excelente conocedor de la Naturphilophie, sigue también a Schelling,: "¿Y si la verdad fuera monstruosa? ¿Y si la verdad fuera la monstruosidad misma, la condición propia, la forma propia, de todo lo monstruoso, de todo lo deforme? Pero, antes que nada, ¿y si la verdad fuera esencialmente monstruosa y deforme en su esencia, si hubiera en la esencia más íntima de la verdad algo esencialmente ajeno a ella, una divergencia de la naturaleza en el seno de la naturaleza, monstruosidad real?”. En Zizek, S.: El frágil absoluto o ¿Por qué merece la pena luchar por el legado cristiano?, Pre-Textos, Valencia, 2009, p. 103 (véase también para esta relación entre lo mostruoso y la decisión, p. 94 y ss; Cfr. Zizek, S.: El acoso de las fantasías, Akal, Madrid, 2011, p. 22 yss.). Para profundizar en el diálogo explícito establecido entre Badiou y Zizek, remito al lector a otro texto de Slavoj Zizek: El espinoso sujeto: el centro ausente de la ontología política, Paidós, Buenos Aires, 2001, donde afirmará lo siguiente:"¿qque ocurriría si lo que Badiou llama el Evento-Verdad es, en su mayor radicalidad, un acto puramente formal de decisión, no solamente no basado en una verdad real, sino en el fondo indiferente al status preciso (real o ficticio) del Evento-Verdad al que se refiere? ¿Que ocurriría si nos estamos ocupando aquí de un componente clave del Evento-Verdad?¿que ocurriría si la verdadera fidelidad al Evento es 'dogmatica' en el sentido preciso de una Fe incondicionalidad, de una actitud que no busca buenas razones, y que por esa misma razón, no puede ser refutado por ninguna 'argumentación'?. Sobre A. Badiou consúltese su clásico: El ser y el acontecimiento, Manantial, Buenos Aires, 1988.

${ }^{7}$ Cf. Marx, K.: “Thesen über Feuerbach”. En: Karl Marx Frühe Schriften, vol. 2, Stuttgart, Cotta, 1971, pp. 1-4.

${ }^{8}$ La relación entre lo real y la realidad efectiva aparece ya en el esquematismo kantiano, íntimamente ligada a la condición de posibilidad de los objetos. Para Kant "lo real" (Realität) significa, como recuerda Heidegger en La tesis de Kant sobre el ser (GA 9, 451), no realidad efectiva sino quiddidad (Sachheit), es decir que lo real hace referencia a aquello que pertenece a la cosa (res), aquello que es parte de su esencia, independientemente de que exista de facto o no. Con este sentido, Kant había integrado la realidad como parte de la categoría de la cualidad porque la realitas implica una concepción de corte sustancialista que desecha por su propio contenido la existencia fáctica. La realidad, entendida como realidad efectiva (Wirklichkeit), estaría referida a la segunda de las categorías "esquematizadas" de la modalidad, que servía de base a juicios existenciales, de acuerdo al efecto resultante de una acción de una sustancia sobre otra. De ahí que la realidad como Wirklichkeit apunte a lo que efectivamente es, esto es, a lo que se da en la experiencia o, dicho de otra manera, a lo que tiene efectos (Wirkung) constatables (Cfr. KrV A 597/B 625 y ss.). Tanto Schelling como Hegel harán buen uso de esta distinción fundamental en sus filosofías y pensarán la realidad como actualidad o facticidad. 
Es bien sabido que Marx desarrolla este núcleo de su pensamiento como crítica al idealismo, en concreto a la filosofía de la historia de corte hegeliano, para la cual la historia de la Humanidad se acerca poco a poco a su destino, que no es otro que la realización de la Razón. El sentido del progreso, término moderno donde los haya y surgido en el XVIII de la mano de Voltaire ${ }^{9}$, tiene que ver precisamente con esta idea: cada instante de nuestro tiempo se considera distinto, mejor, superior que el anterior, al que engloba y da sentido. La Humanidad en su conjunto, no los hombres individuales, constituye el Sujeto ideal de una Historia que, en progreso constante, gana en calidad con los años, como el buen vino, y culmina, tras una larga maduración, con un estado de "perfección" o de "consumación". Llegaremos al fin de la historia pase lo que pase, pese a guerras e infortunios (piénsese en las "astucias de la razón” descritas por Hegel), puesto que, junto con el tiempo, se despliega la alfombra roja de la historia en cuyo final brindaremos triunfalmente con el cáliz de los espíritus, el mismo con el que Hegel, parafraseando unos versos de Schiller, concluye la Fenomenología del espíritu $(1807)^{10}$. Cerrado y concluido, el fin de la historia no significa entonces el acabamiento de ésta, pero sí su culminación. La Razón teje así su red, puro constructo, en y como propia historia, y se manifiesta "linealmente" (como camino del progreso) y sin resto en todo su esplendor, puesto que todo queda "asimilado" dentro del sistema. Todo queda revelado.

La correcta orientación de este progreso racional (que culmina con el grado más elevado de perfección), vendría anunciado por los "acontecimientos" históricos, que Kant denominará "Begebenheiten", esto es, literalmente "donaciones de sentido"11. Aunque en un principio, en el momento del "acontecer", algunos de estos aconteci-

\footnotetext{
${ }^{9}$ No en vano fue Voltaire quien acuñó por vez primera el término "filosofía de la historia" en su Ensayo sobre las costumbres y el espiritu de las Naciones (1769), texto en el que trataba de ofrecer, de forma secularizada y contra la teología política de Bossuet, la historia filosófica de un proceso civilizatorio a escala mundial basado en la razón y gobernado por las ciencias, la técnica, la moral, las leyes y el comercio, es decir, por las formas de dominio del hombre frente al mundo, que queda troquelado por la intervención "racional" del hombre, frente al "material" ofrecido por una naturaleza "dispuesta" para la humanidad. Sobre el origen de la conciencia histórica y la idea de progreso cf. Muñoz, J.: Filosofía de la historia, Madrid, Biblioteca Nueva, 2010, pp. 65 y ss.

10 "La meta, el saber absoluto o el espíritu que se sabe a sí mismo como espíritu tiene como su camino el recuerdo de los espíritus como son en ellos mismos y como llevan a cabo la organización de su reino. Su conservación vista por el lado de su ser allí libre, que se manifiesta en la forma de lo contingente, es la historia, pero vista por el lado de su organización conceptual es la ciencia del saber que se manifiesta, uno y otro juntos, la historia concebida, forman el recuerdo y el calvario del espíritu absoluto, la realidad efectiva, la verdad y la certeza de su trono, sin el cual el espíritu absoluto sería la soledad sin vida; solamente: del cáliz de este reino de los espíritus / rebosa para él su infinitud". En GW 9: 434. Hay traducción en Hegel, G.W.F.: Fenomenología del espíritu, FCE, Madrid, 1999, trad. de W. Roces, p. 473. Trad. modif.

${ }^{11}$ Cf. Duque, F.: Historia de la Filosofía moderna. La Era de la Crítica, Akal, Madrid, 1998, p. 152.
} 
mientos pueden parecer incomprensibles, a posteriori son susceptibles de ser analizados para averiguar de dónde surgen y qué lo que los ha producido, sin embargo su importancia vendría del hecho de constituir a ojos de Kant un signum prognostikon, ${ }^{12}$ es decir, son hechos que permiten saber hacia dónde vamos, de lo contrario, los sucesos serían puramente contingentes, azarosos, mera sucesión sin sentido interno. Es importante hacer notar que, tal y como es entendido por Kant, el acontecimiento llevaría a presencia la esencia que vertebra la historia: parusía, dando a ésta sentido. Pero nada es azaroso, decíamos, no porque estos acontecimientos permitan entrever el télos que dirige la historia, sino porque, más que "momentos puntuales" o "puntos claves" del devenir histórico, que anuncian el futuro por llegar y se insertan en una red de sentido, suponen la punta de un iceberg que además de dar señales del futuro, son -dicho con Hegel- "manifestaciones" de la Razón en la Historia. Este sería el caso, por ejemplo, de la Revolución Francesa que supondría una prueba del acertado curso de una Razón que se manifiesta ahora como libertad. Esta idea será, por cierto, la que llevaría a Francis Fukuyama a sostener en 1989 que el fin de la historia había llegado ya con la caída del bloque soviético y el final de la guerra fría: "El triunfo de Occidente, de la idea occidental, queda patente ante todo en el total agotamiento de alternativas viables al liberalismo occidental [...] Es posible que lo que estamos presenciando no sea simplemente el final de la guerra fría o el ocaso de un determinado periodo de la historia de la posguerra, sino el final de la historia; es decir, el último paso de la evolución ideológica de la humanidad y de la universalización de la democracia liberal occidental como forma de gobierno humano"13. Que dicho triunfo implicara que todos los cataclismos (terror, opresión, exterminación, genocidio) fueran sólo "hechos" empíricos, no restaba, según Fukuyama, sentido racional al curso de la historia ni validez alguna a su lectura ${ }^{14}$.

Curiosamente, la idea de "fin de la historia" fue retomada y reelaborada por el marxismo (el mismo que critica Fukuyama en su lectura de Hegel). Marx, sin embargo, aun siguiendo la idea de "fin de la historia" cree que éste sólo puede alcanzarse rasgando la realidad tejida por el proceso abstracto de la razón, es decir que hemos de despertar del engaño o abotargamiento producido por la inhalación del aquel opio del pueblo y darnos cuenta de que nuestra realidad está construida, es artificial, y que, por tanto, puede ser derruida y reconstruida. Es aquí donde tiene sentido la reacción experimentada por Brecht de "pasión por lo Real" con la que comenzábamos este texto: es el gesto violento el que deja entrever, entre escombros de la realidad artificial, lo "ver-

\footnotetext{
${ }^{12}$ AK. VII, 84 (Der Streit der Fakultäten). Hay traducción al castellano: Immanuel Kant, El conflicto de las facultades, Madrid, Alianza Editorial, 2003.

${ }^{13}$ Fukuyama, F.: “EEl Fin de la Historia?”. En Revista Claves de la razón práctica, nº1, 1990, p. 85.

${ }^{14}$ Cf. Fukuyama, F.: El fin de la historia y el último hombre, Barcelona, Planeta, 1992, p. 96.
} 
daderamente auténtico". Sólo hay que recordar, para dar cuenta de lo acertado de la lectura de Zizek, el final, terrible, de la pieza teatral del propio Brecht Tambores en la noche (1918-1920): "Todo esto no es más que puro teatro. Simples tablas y una luna de cartón. Pero los mataderos que se encuentran detrás, ésos sí son reales"'15.

Esta distinción entre la "pasión por lo Real" característica del siglo XX y lo que podemos denominar "la pasión por lo ideal" del XIX se vertebra en torno a lo que debe ser entendido por realidad y que Zizek emplea para leer nuestro tiempo: el tiempo de lo virtual. Pero lo interesante -y ésta es nuestra propuesta- es que además, de forma no explícita, conecta dos problemas aparentemente desvinculados: por un lado, y por lo ya dicho, la construcción de realidades históricas (dentro del ámbito de la filosofía de la historia) y, por otro, la pregunta ontológica por el "ser" de la realidad y de lo Real, es decir, de la constitución de nuestra realidad y de lo ente (plano metafísico); dos problemas que se conectan a través de un punto de unión que se encuentra en la filosofía de Schelling, un punto que, de seguir al propio filósofo de Leonberg constituye "el más importante para la filosofía desde Platón": lo "no-ente" (das Nichtseyende $)^{16}$. Podemos hablar entonces no sólo de desarrollos de la filosofía schellinguiana, sino también de su actualidad y relevancia para abordar problemas de la filosofía contemporánea, sobre todo los planteados por Zizek y Baudrillard. Efectivamente, si según la "filosofía de la historia" de origen hegeliano los acontecimientos anuncian el fin racional de la historia, con Schelling podemos conformar una nueva concepción de la historia en la que además de "acontecimientos", hay otra cosa, algo que explicaría la relación entre la construcción de la historia y el mundo de lo virtual y del espectáculo y que, supondría que la propia historia -y, por extensión, el supuesto "progreso" al que tiende la Humanidad- quedaría adulterado. La historia no va, de ese modo, encaminada hacia lo que creemos interpretar en la realidad.

La propuesta de Schelling en torno al sistema y a la forma de comprender el Absoluto será radicalmente diferente a la de Hegel. No hay una revelación de lo profundo, sino una parte profunda y oscura bajo la revelación: aunque la historia constituya también el camino de conformación y toma de conciencia de un "Sujeto" de la misma, no hay una manifestación plena, como si todo fuera susceptible de devenir consciente, es decir, "manifiesto", sino que la historia está compuesta también por niveles subterráneos, sustratos inconscientes y, por tanto irreductibles que, al mismo tiempo, son constitutivos del Sujeto, que son "efectivos" aunque nunca lleguen a tener una entidad de suyo en la existencia.

${ }^{15}$ Brecht, B.: Tambores en la noche. En Teatro completo, 1, Madrid, Alianza, 2000.

${ }^{16}$ WA I 36.37. Hay trad. al castellano a cargo de Jorge Navarro en: Schelling, F.W.J.:Las Edades del Mundo, Madrid, Akal, 2001, p. 61. Schelling atribuirá a su filosofía de la identidad haber reintroducido en la filosofía el concepto de lo no-ente, tras la ignorancia y el rechazo del idealismo. Cf. Philosophie der Offenbarung, Frankfurt, Suhrkamp, 1977, pp. 113-114. 


\section{Pasión por la apariencia}

Esa "otra historia de la conciencia" será la que haga que Zizek considere que Schelling ha llevado a cabo una revolución filosófica ${ }^{17}$ de la que se sirve para explicar la virtualización de nuestra experiencia. De seguir los planteamientos de Zizek en $E l$ acoso de las fantasías (1997), El frágil absoluto (2000) o Bienvenidos al desierto de lo real (2002), la realidad se relacionaría con el tejido o contexto en el que estamos insertos o integrados, es decir, con una red de coordenadas simbólicas que determina nuestra experiencia de la realidad (nuestro mundo "cotidiano") y bajo ella, latente, se encontraría lo Real, entendido como lo "auténtico" pero al mismo tiempo como lo impenetrable cuya visión puede convertir en piedra al sujeto, como hiciera la medusa si es mirada directamente a los ojos, pero que sólo se tornaría como amenaza por el sujeto que la experimenta ${ }^{18}$. Lo Real, frente al constructo de la realidad, es, pues, el abismo $^{19}$. Como aquella película de Michael Gondry, Eternal Sunshine of the Spotless Mind (2005), traducida en España como Olvídate de mí, por mucho que se esmere, el personaje principal no puede evitar que los recuerdos borrados mediante una máquina diseñada para eliminar "restos dolorosos", afloren de nuevo, como la humedad de una pared que se obstina en no desaparecer. La realidad creada artificialmente no puede esquivar de este modo los embates de un inconsciente que se resiste a acomodarse a una nueva realidad impuesta, aunque ésta sea incluso autoimpuesta (o precisamente por eso). Lo Real aparece en escena pero "tiene el status de otra apariencia: precisamente porque es real, es decir, a causa de su carácter traumático/excesivo, somos incapaces de integrarlo en (lo que experimentamos como) nuestra realidad y, por lo tanto, nos vemos obligados a experimentarlo como una aparición de pesadilla" ${ }^{20}$. Juego de espejos, para camuflar aquello que es verdaderamente real, lo Real se maquilla como sueño de una razón que, como dijera Goya, produce monstruos. E1

\footnotetext{
${ }^{17}$ Zizek, S.: "Everything You Always Wanted to Know about Schelling (But Were Afraid to Ask Hitchcock)". En Wirth, J.M.: Schelling Now. Contemporary Readings, Indiana University Press, 2005, p. 33.

${ }^{18}$ En El frágil absoluto Zizek establecerá la siguiente distinción entre la realidad y lo Real en Lacan: "la "realidad" es la realidad social de las personas concretas implicadas en la interacción, y en el proceso productivo, mientras que lo Real es la inexorable lógica espectral". En Zizek, S.: El frágil absoluto, op. cit. pp. 25-26.

${ }^{19}$ Zizek desarrolla tres nociones o categorías de lo Real: lo Real real, que será el tema de este texto, lo Real imaginario que designaría no la ilusión de lo Real, sino aquello que, sin saber explicar, nos causa rechazo, y lo Real simbólico asociado a aquello que desde la razón o la ciencia no puede ser integrado en nuestro horizonte de sentido, como, por ejemplo, la física cuántica, que no puede ser explicada por sí misma sino sólo traducida a partir de fórmulas que funcionan. Cf. Zizek, S.: Arriesgar lo imposible. Conversaciones con Glyn Daly, Madrid, Trotta, 2006, pp. 68 y ss.

${ }^{20}$ Zizek, S.: Bienvenidos al desierto de lo real, op. cit., p. 20.
} 
siglo XXI se caracterizaría de este modo por una pasión por la apariencia, como dice el propio Zizek, pero también, y por lo que veremos, por el simulacro, como bien viera Baudrillard, ambos dentro de lo que, desde Debord ${ }^{21}$, se denomina sociedad del espectáculo $^{22}$ puesto que, en la ilusión de transparencia en nuestro mundo de información y globalización, creemos tener un acceso directo a todo cuanto sucede en nuestra realidad, pero se confunde "inmediatez" con "transparencia" y "transparencia" con "autenticidad". Efectivamente nuestro acceso a la realidad está mediatizado por los medios que transmiten imágenes virtuales en tiempo real. Primera ilusión de inmediatez, como si la lente de una cámara no supusiera ya una decisión de perspectiva, como señala Susan Sontag, un filtro entre dos puntos ${ }^{23}$. La transmisión en "tiempo real", que nunca es real del todo puesto que presenta un desajuste temporal, no asegura ni la autenticidad de la imagen, ni incluso su caracter ficticio, antes bien, lo único que garantiza es la imagen misma, que puede referirse a algo realmente existente, pero que también puede alejarse de su referente hasta el infinito, como en la famosa escena final de The lady from Shanghai de Orson Welles (1948). Segunda ilusión: la de transparencia. No hay por tanto una Pasión por lo Real auténtica, sino una pasión falsa, basada en otro juego de apariencias en el que se presenta como Real lo que se construye y representa como tal. Sin embargo lo Real en sí mismo es, por definición, inasible $\mathrm{y}$, por tanto, indomeñable.

En el campo de la filosofía de la historia podría decirse de este modo que en las "realidades históricas" quedarían entretejidos acontecimientos auténticos fácilmente integrables, acontecimientos reales tomados como ficticios, que serían irrupciones de lo Real disfrazadas para ser integradas en el sistema, aunque sea adulteradamente; y

\footnotetext{
${ }^{21}$ Aunque Debord se sitúa en un ámbito teórico alejado en muchos aspectos de aquel en el que se sitúan Zizek o Baudrillard, y la "sociedad del espectáculo" ha de asociarse, en la línea hegeliano-marxista del fin de la historia, con sus análisis sobre la alienación de los trabajadores en el tiempo total de la vida de los hombres y el efecto del dominio del capital a través de la teconología, su reflexión sobre las consecuencias de lo espectacular en la historia pueden ser puestas en relación con el tiempo de simulacro, de ocultación de la realidad y del juego realidad/ficción con la que se entreteje la historia. Recordemos, por ejemplo, un fragmento de La sociedad del espectáculo: "El espectáculo no debe oponerse en abstracto a la actividad social efectiva, pues tal desdoblamiento está en sí mismo desdoblado. El espectáculo, que invierte lo real, es efectivamente producido en cuanto tal. La realidad vivida se halla materialmente invadida por la contemplación del espectáculo, y al mismo tiempo alberga en sí el orden espectacular, otorgándole su positiva adhesión. La realidad objetiva se presenta en sus dos dimensiones. Cada noción fijada de este modo no tiene más sentido que la transición a su opuesto: la realidad surge en el espectáculo, y el espectáculo es real. Esta alienación recíproca es la esencia y el sustento de la sociedad actual”. En Debord, G.: La sociedad del espectáculo, Pre-Textos, Valencia, 2012, p. 40.

${ }^{22}$ También el propio Zizek: "La verdad última del universo capitalista utilitarista y desespiritualizado es la desmaterialización de la propia "vida real", su inversión en un espectáculo espectral". En Bienvenidos al desierto de lo real, op. Cit, p. 17.

${ }^{23}$ Cf. Sontag, S.: Sobre la fotografía, Madrid, Debolsillo, 2009.
} 
acontecimientos ficticios tomados por auténticos. Los primeros pueden ser denominados acontecimientos en el sentido fuerte del término ${ }^{24}$, los segundos espectros y los terceros simulacros. En esta exposición trataré de analizar los dos últimos, el espectro y el simulacro. Si bien el único que "es" como tal es el acontecimiento y como tal ejerce la función de lo "ente" según la tradición ontológica, es decir, según el libro IV

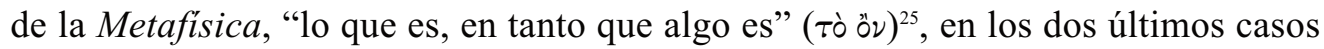
nos encontraríamos con formas de lo "no-ente": no siendo, son o, mejor, son "efectivos" o, aún mejor, pese a no ser, existen. Por tanto habría que hablar de una "efectividad" (Wirklichkeit) de lo no-ente, concepto que para Schelling tendrá dos sentidos, muy alejados de la privación de ser o de la deficiencia, y que nos ayudarán a entender la construcción de realidades históricas y el sentido con el que poder entender tanto "el espectro" como el "simulacro".

\section{El espectro}

Así la realidad, como escenario "controlado" en el que nos movemos con tranquilidad, disfraza de monstruoso lo que es verdaderamente monstruoso. Sin embargo, camuflado de ficticio, eso Real se convierte en el espectro, en un "espectro irreal de pesadilla" por emplear las palabras de Zizek, que amenaza y atenaza constantemente, como sombra que se cierne, y, como tal, se presenta como origen de lo traumático, dado que, pese a su supuesta "irrealidad", tiene unos efectos (Wirkung); un espectro que pese a "que no era posible" ha devenido efectivo (wirklich): "en nuestra existencia cotidiana, estamos inmersos en la «realidad», y esta inmersión es perturbada por síntomas que dan testimonio del hecho de que otro nivel de nuestra psique, reprimido, se resiste a esta inmersión" ${ }^{26}$. Ahora bien ¿qué es esto Real que no siendo, es? o, dicho de otra forma ¿qué es aquello que no siendo comprensible por la razón, que se escapa y permanece inasible, sin embargo le afecta, tiene efectos en ella? Zizek afirmará: "Para comprender esta paradoja, debemos tener en cuenta que lo opuesto a la existencia no es la no existencia, sino la insistencia: lo que no existe, continúa insistiendo, tendiendo a la existencia (el primero en articular esta oposición fue, por supuesto, Schelling cuando en su Tratado sobre la libertad humana, introdujo la distinción entre existencia y fundamento de la existencia). Cuando perdemos una oportunidad ética crucial, y no logramos hacer ese gesto que "lo cambiaría todo", la propia no

\footnotetext{
${ }^{24}$ Para profundizar en el "acontecimiento", me permito remitir a mi artículo "Blow up. Evento, acontecimiento, crisis". En Cadahia, L.-Velasco, G.: Norma y crisis de la filosofía, Madrid, Katz Editores, 2012, pp. 123-137.

${ }^{25}$ Aristóteles: Metafísica, Libro IV, 1003a-1003b.

${ }^{26}$ Zizek, S.: Bienvenidos al desierto de lo real, op. cit., p. 19.
} 
existencia de lo que debería haber hecho me atrapa para siempre: aunque lo que he hecho no existe, su espectro sigue insistiendo" 27 . Este espectro tiene que ver no sólo con el arrepentimiento ("lo que debería haber hecho"), sino también con una amenaza no materializada, con aquello que puede venir y caer sobre nosotros en cualquier momento, también como la aparición súbita de aquello que, debiendo permanecer oculto, de pronto, se manifiesta, se hace efectivo para desaparecer de nuevo y dejar horadada la realidad. El trauma. Por eso Zizek comprende el atentado contra el World Trade Center como el golpe que la irrupción de lo Real ha asestado contra nuestra realidad y puede afirmar que "Estados Unidos obtuvo aquello con lo que había estado fantaseando" "28. Lo Real tendría que ver de este modo con aquello que se encuentra en nuestra psique y aparece como síntoma de un miedo inconsciente que, al devenir consciente, se materializa como fantasma. El "fantasma" encarna así ese miedo hacia lo que se escapa de la red racional con la que tejemos nuestra realidad. Zizek recordará en este sentido la definición lacaniana de lo Real como lo imposible, según la cual la historia fantasmática y espectral está siempre referida a un acontecimiento traumático "que no puede inscribirse en el propio espacio simbólico abierto precisamente por su intervención. Como ha señalado Lacan, ese acontecimiento traumático espectral "no cesse pas de ne pas s'écrire", no deja (o cesa) de no escribirse (de no inscribirse) y, por supuesto, precisamente como tal, como no existente, persiste: es decir, la presencia espectral sigue acosando a los vivientes" "29. Sabemos sin embargo, nos dice Zizek, que algo no funciona en nuestro teatro. Hay algo más real que la realidad.

\section{Entramos en el primer sentido de lo no-ente en Schelling.}

La alusión al Escrito sobre la libertad humana de 1809 se refiere al concepto de "resto irreductible" (nie aufgehende Rest) que Schelling desarrolla al analizar la relación entre la existencia y su fundamento y que constituye el pilar central de su investigación ${ }^{30}$. Zizek, de hecho, dedicará un ensayo a esta temática sobre "el resto" en 1996, The indivisible remainder ${ }^{31}$, centrado sobre todo en Las Edades del Mundo, la gran obra inacabada de Schelling, con tres versiones $(1811,1813$ y 1815) y largos desarrollos hasta su

\footnotetext{
${ }^{27}$ Ibid, p. 22. También en

${ }^{28}$ Ibid, p. 18.

${ }^{29}$ Zizek, S.: El frágil absoluto o ¿Por qué merece la pena luchar por el legado cristiano?, op. cit., pp. 86-87.

${ }^{30}$ Cf. SW I/7, 357; hay traducción al castellano de A.Layte y H. Cortés en F.W.J. Schelling: Investigaciones sobre la esencia de la libertad humana y los objetos con ella relacionados, Barcelona, Anthropos, 2000, pp. 161-163.

${ }^{31}$ Zizek, S.: The indivisible remainder. On Schelling and related matters, Londres, Verso, 1996.
} 
filosofía tardía ${ }^{32}$. La distinción Grund/Existenz quiere dar cuenta del proceso de despliegue del Absoluto que Schelling entiende siempre vinculado al concepto de historicidad y que hace que el Absoluto no sea ya algo dado o hecho, algo "inmediato", sino que se vaya haciendo a través de un proceso de autoconstrucción y de formación que no sólo implica la constitución "por fases" de la identidad y de la subjetividad y la paulatina toma de conciencia del Absoluto -es decir, del camino de la inconsciencia (Unbewußtheit) a la conciencia (Bewußtsein) ${ }^{33}$, de ahí, por cierto, el título del clásico estudio de Jankélévitch, La odisea de la conciencia ${ }^{34}$-, sino también la construcción de la propia realidad, del "salir a la existencia" de las cosas. Todo cuanto existe aparece dentro del proceso de despliegue del Absoluto, que en sentido pleno se entiende no como punto de partida, sino como punto de llegada ${ }^{35}$ en el que este Absoluto-Sujeto alcanza su consumación (Vollendung) y su efectiva realización (Verwirklichung) a través de la máxima autorrevelación (Selbstoffenbarung). Ése es el concepto, presentado por Schelling de un Absoluto (o Dios) en devenir ${ }^{36}$, de lo "Absoluto derivado" ${ }^{37}$. Ahora bien, si se trata de un punto de llegada, ¿qué encontramos al comienzo? ¿cómo se desencadena el proceso? ¿qué significa que las cosas son y existen únicamente dentro de este devenir? Y, finalmente ¿qué sentido tiene hablar de un "resto irreductible" cuando se afirma que el proceso tiene como meta la manifestación y la efectiva realización del Absoluto?

Schelling comenzará el Escrito sobre la libertad respondiendo a las acusaciones de ateísmo y de panteísmo vertidas por Schlegel en su Indierbuch de 1808, en el cual, siguiendo la caza de brujas iniciada y avivada por Jacobi, identificaba al spinozismo con el ateísmo ${ }^{38}$. El punto central de la argumentación desarrollada en el texto de 1809

${ }^{32}$ Cf. Carrasco-Conde, A.: "El Sistema de los tiempos y el Epos de la historia: Schelling y la historicidad del absoluto“. En: Revista Bajo Palabra (2009), Epoca II, N. 4, pp. 99-106.

${ }^{33} \mathrm{SW} \mathrm{I} / 7,361 ; 171-173$.

${ }^{34}$ Cf. Jankélévitch, V.: L'Odyssée de la conscience dans la dernière philosophie de Schelling, Paris, Félix Alcan, 1933.

${ }^{35}$ La idea de "punto de llegada" asociada al Absoluto aparece en Marquet, F.: Liberté et existence. Étude sur la formation de la pensée de Schelling, Paris, Gallimard, 1973, p. 396 y ss.

${ }^{36} \mathrm{Cf}$. SW I/7, 358-359; 165.

${ }^{37} \mathrm{Cf}$. SW I/7, 347; 139.

${ }^{38}$ Hay bibliografía abundamente sobre esta polémica: Die Hauptschrift zum Pantheismusstreit zwischen Jacobi und Mendelssohn, editado por Heinrich Scholz, Verlag von Reuther \& Reichard. Berlin, 1916 en la que se encuentra una recopilación casi exhaustiva de los documentos de esa polémica. También el estudio de Kurt Christ: Jacobi und Mendelssohn. Eine Analyse des Spinozastreits. Königshausen \& Neumann. Würzburg, 1988; así como el clásico estudio de Hans Hölters: Der spinozistische Gottesbegriff bei M. Mendelssohn und J.H. Jacobi und der Gottesbegriff Spinozas. Universitas-Archiv. Verlag-Anstalt Heinr. \& J. Lechte / Emsdetten. 1938. En castellano remitimos al estudio más reciente, donde se analizan varios de los episodios, desde Mendelsohn a Schelling: Cf. Rivera de Rosales, J - Cubo Ugarte, O.: La polémica sobre el ateísmo. Fichte y su época, Madrid, Dyckinson, 2009. También destacamos la obra de José Luis Villacañas: Nihilismo, especulación y cristianismo. Ensayo sobre los orígenes del irracionalismo contemporáneo, Barcelona, Anthropos, 1989. 
se vertebra en torno a la afirmación de Schlegel: "el panteísmo es el sistema de la pura razón" ${ }^{39} \mathrm{y}$, por ello fatalista. Schelling afirmará, no sin ironía, recordando estas palabras de Schlegel: "el único sistema posible de la razón es el panteísmo, pero éste conduce inevitablemente al fatalismo. Es innegable lo maravilloso de la invención de estos nombres generales mediante los cuales se puede designar de una sola vez toda una concepción" ${ }^{40}$. Esta idea surge de la identificación llevada a cabo por Lessing según la cual la única filosofía que puede ser considerada como tal es la de Spinoza ${ }^{41}$ y dado que su sistema, según se afirma, sólo puede ser tachado de panteísta, toda filosofía es panteísta (recordemos que para Spinoza, según la Parte I de la Ética, Proposiciones XIV y XV, la única sustancia que puede concebirse es Dios y que, por tanto, todo cuanto es, es en Dios). De ese modo, tal y como hará ver Jacobi, reaccionando contra Lessing e iniciando la polémica, la filosofía de Spinoza (y la de Lessing, Fichte, Kant e incluso Schelling) es fatalista y atea. Todo es Dios. Pero si todo es Dios, no hay lugar para la libertad dentro del sistema: seríamos parte de un engranaje, de un todo, que nos haría seres pasivos dependientes de la causalidad absoluta de un único Ser. Schelling solucionará este problema explicando qué debe entenderse por spinozismo y por qué su sistema no debe identificarse con él ${ }^{42}$. No se trata de que "Todo sea Dios"

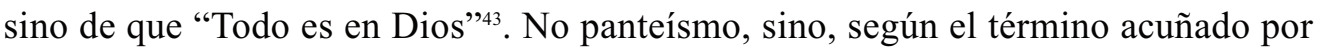
Krause, panenteísmo. Los seres son, de este modo, consecuencia de la autorrevelación de Dios, pero no Dios mismo. Aparecen en el proceso de su despliegue, pero no pueden ser identificados con Él, con el Sujeto Absoluto, o, dicho de otra manera, los seres están en el sistema, pero no son identificables con él, son otra cosa diferente, o incluso, si se quiere, somos en el universo pero no somos el universo.

Si todo cuanto existe, existe en y por el proceso de despliegue o de devenir del Absoluto en su autorrevelación y no nos identificamos con él (no somos Dios), hay algo más, además de la propia Existencia de ese Sujeto, algo más que propicia el proceso pero que tampoco se identifica con el proceso mismo, de ahí la afirmación de Schelling: "Reconocemos [...] que el concepto de devenir es el único apropiado a la

\footnotetext{
${ }^{39} \mathrm{KA}, \mathrm{VIII}, 249$.

${ }^{40} \mathrm{SW} \mathrm{I} 7,338 ; 117$. No trataré aquí esta polémica, por salirse del objeto de este artículo. Un estudio pormenorizado de la respuesta de Schelling a Schlegel, centrado en el Escrito sobre la libertad, puede consultarse en Carrasco-Conde, A.: "Panteísmo y Panenteísmo: Schelling, Schlegel y la polémica en torno al panteísmo". En Daimon. Revista Internacional de Filosofía (2011), no 54. Septiembre/Diciembre, pp. 93-109.

${ }^{41} \mathrm{Sp}$.-Br, 18; hay traducción al castellano de J.L. Villacañas: Cartas a Mendelssohn y otros textos, Madrid, Círculo de Lectores, 1996, p. 89.

${ }^{42}$ En todo caso, según Schelling, el sistema de Spinoza no puede tacharse de fatalista. Su problema estriba no en que sitúe a las cosas en Dios, sino en que sean cosas, es decir, por la falta de vida y el caracter mecánico que otorga a la naturaleza. Cf. SW I/7, 349; 143.

${ }^{43}$ Cf. SW I/7, 339-340; 119-121.
} 
naturaleza de las cosas. Pero éstas no pueden devenir en Dios considerado de modo absoluto, puesto que son distintas de Él toto genere o, para decirlo más correctamente, son distintas de Él infinitamente. Para estar escindidas de Dios tienen que devenir en un fundamento distinto de Él. Pero como no puede existir nada fuera de Dios, esta contradicción sólo puede resolverse diciendo que las cosas tienen su fundamento en aquello que, en Dios mismo, no es Él mismo, esto es, en aquello que es el fundamento de la existencia de Dios" ${ }^{\prime 4}$.

Schelling había ya distinguido previamente entre "el ser, en cuanto que existe" y el "ser en cuanto mero fundamento de la existencia" 45 , los dos términos a los que alude Zizek y que están al comienzo del proceso de despliegue, pero también al final, de ahí la relación, como veremos, con aquel "resto irreductible". El "ser, en cuanto que existe" es Dios, el Sujeto, considerado de forma absoluta en su paulatino camino de ser sí mismo, de devenir consciente de sí, mientras que "el fundamento de su existencia" es lo que deja atrás, pero que no consigue eliminar, ni superar, sino que permanece inseparablemente unido a él como base o fondo de provisión y que, aunque no es Dios mismo, sí es la oscuridad previa a partir del cual comienza a ser sí mismo. Schelling lo denominará la Naturaleza -en Dios. Como Grund es fundamento del proceso en el sentido "real" del término y como tal, no puede salir de sí nunca, ni lógica ni realmente. Para explicar esta relación, Schelling se servirá de la analogía con la gravedad y con la luz: la primera implica siempre un movimiento de contracción, aún más de retracción, y la segunda, de expansión o de donación ${ }^{46}$. El fundamento es siempre lo

${ }^{44} \mathrm{SW}$ I/7, 359; $165-167$.
${ }^{45} \mathrm{SW} \mathrm{I/7}, 357 ; 161-163$.

46 "Esta relación puede ilustrarse por medio de la analogía de la relación existente en la naturaleza entre la fuerza de la gravedad (Schwerkraft) y la luz. La fuerza de gravedad precede a la luz como su fundamento eternamente oscuro, que no es acto él mismo y que huye en la noche mientras se levanta la luz (lo existente). Ni siquiera la luz rompe por completo el sello bajo el cual permanece encerrada". SW I/7, 358; 163. Es interesante hacer notar que lo que Schelling opone a la luz es la gravedad y que cuando alude a ésta como oscuridad, este último término no ha de entenderse en términos privativos como falta de luz, sino como aquella fuerza que, por su absoluta contracción, se opone positivamente a ella (según la célebre -y denostadaconcepción de la "tiniebla" o Finsternis en Goethe). Dado el objeto de nuestro texto, no nos detendremos en profundizar en esta importante distinción. Remitimos por ello, entre la abundante bibliografía sobre el tema, a los trabajos de O. Höffe- A. Pieper (Eds.): Über das Wesen der menschlichen Freiheit, Berlín, Akademie Verlag 1995 y, dentro de esta obra colectiva al de O. Marquard: "Grund und Existenz in Gott"; también M. Baumgartner - W.G. Jacobs (Eds.): Schellings Weg zur Freiheitsschrift. Legende und Wirklichkeit, Stuttgart, Fromman-holzboog 1996; J. Hennigfeld: Friedrich Wilhelm Joseph Schellings > Philosophische Untersuchungen über das Wesen der menschlichen Freiheit und die damit zusammenhängenden Gegenstände<, Darmstad, Wissenchaftliche Buchgesellschaft 2001. Con ocasión del bicentenario han sido publicados recientemente dos trabajos de gran interés: G. Wenz: Das Böse und sein Grund. Zur Rezeptionsgeschichte von Schellings Freiheitsschrift 1809: Vorgelegt in der Sitzung vom 9. Juli 2010, Múnich, Bayerische Akademie der Wissenschaften 2010; S. Peetz - R. Elm: Freiheit und Bildung: Schellings Freiheitsschrift 1809-2009, Paderborn, Fink 2011; Ferrer, P.-Pedro, T. 
que se retrae, lo que posibilita la manifestación de lo existente al servirle de fondo y de base contra el que luchar para salir de la oscuridad del inconsciente. Es el ansia de ser (Sehnsucht), el deseo (Begierde $)^{47}$, lo que inicia la revelación, pero al mismo que genera el movimiento expansivo de la existencia (voluntad expansiva), produce un movimiento de contracción hacia sí mismo al querer ser sí mismo, al apuntar a su ser más propio (voluntad contractiva) ${ }^{48}$. No en vano Schelling afirmará que en esta particular odisea no hay superación, cancelación o asunción de fases o figuras previas (Aufhebung) sino un esfuerzo constante de sometimiento (Überwindung) que nunca puede ser integrado en la parte "racional" del sistema. Al mismo tiempo que se da la conciencia y la razón, hay que luchar contra lo que Freud denominará "las pulsiones" y que permanece, con una fuerza activa propia como "latencia". Esto que permanece al fondo y como fondo, siempre escapándose de la luz de la conciencia y, por tanto, de la pura razón, es precisamente lo carente de regla ${ }^{49}$, es decir, aquello a lo que no puede darse medida y que no puede analizarse o catalogarse.

El sujeto que, como autoconsciencia de sí, es ya transparente, se enfrenta de este modo con la negrura de un fondo, el suyo, insondable para él mismo, que no puede ser eliminado: si lo fuera el sujeto ya no sería -eliminaría una parte de lo que es-, tampoco tendría suelo a sus pies ni base sobre la que poder elevarse en esa curvación sobre sí mismo que le permite realizarse efectivamente en la historia, ni tampoco tendría posibilidades de hacerlo. Este terco resto irreductible (nie aufgehende Rest) que "ni con el mayor esfuerzo se deja disolver por el entendimiento"-como afirmará Schelling ${ }^{50}$ - es lo que queda siempre tanto en el proceso como en la completa realización del sujeto y que no ha podido ser ni asimilado ni tan siquiera rozado por la actividad troqueladora de la razón y del entendimiento: no es que sea irracional ${ }^{51}$ sino que la

(Eds): Schellings Philosophie der Freiheit. Studien zu den Philosophischen Untersuchung über das Wesen der menschlichen Freiheit, Würzburg, Ergon, 2012. También citamos, por imprescindible, el estudio de M. Heidegger: Schellings Abhandlung über das Wesen der menschlichen Freiheit (1809), Tubinga, Max Niemeyer 1971.

${ }^{47}$ Cf. SW I/7, 359, 167.

${ }^{48}$ En este movimiento los conceptos de mismidad (Selbstheit), ansia (Sehnsucht) y egoísmo (Selbstsucht) son fundamentales. Para profundizar en la relación existente entre ellos, me permito remitir a: Carrasco-Conde, A.: "1809: Die Figur Napoleons und der Begriff des Bösen in der Freiheitsschrift”, en Ferrer, P.-Pedro, T. (Eds): Schellings Philosophie der Freiheit. Studien zu den Philosophischen Untersuchung über das Wesen der menschlichen Freiheit, op. cit., pp. 71-81.

${ }^{49} \mathrm{Cf} . \mathrm{SW} \mathrm{I} / 7,359 ; 167$

${ }^{50} \mathrm{SW} \mathrm{I} / 7,360 ; 169$.

${ }^{51}$ Lukács comenzará su historia de la irracionalidad con Schelling, precisamente porque entenderá este fundamento del sistema como irracional. En Lukács, G.: Die Zerstörung der Vernunft; en: Werke. vol. 9. Luchterhand. 1962. Hay traducción al castellano de Wenceslao Roces: El asalto a la razón. La trayectoria del irracionalismo desde Schelling hasta Hitler. Grijaldo. Barcelona. 1976. 
razón, literalmente, "no puede con él”, permanece así, puro en su pura retracción, pero siempre como amenaza. Por lo visto, el "Resto" no es un residuo, por tanto, que haya sido digerido por la razón y desechado, el desperdicio, sino más bien el resquicio que punta a esa relación inseparablemente necesaria entre el Grund y la Existencia. De esa forma, siempre está, aunque nunca es. No es una nada, pero tampoco es un ente. Es, como dirá Schelling en Las Edades del Mundo, lo "no-ente": "Esta relación de la otra voluntad [contractiva] ha confundido a los observadores de diversas maneras. A unos, haciéndoles creer que esta fuerza que se comporta como no-ente es también en sí misma, [...] una nada. De ahí que los idealistas suelan tratarla simplemente como una fuerza que no existe de ninguna manera" ${ }^{52}$. Para Schelling lo no-ente no supone carencia o privación, sino un modo diferente de ser que se opone activamente al ser de lo ente: "lo no-ente no es carencia absoluta de esencia, es sólo la esencia contrapuesta a la esencia auténtica, pero no por ello menos positiva a su manera; si aquella es la unidad, es la oposición y en concreto la oposición por excelencia o en sí misma" ${ }^{53}$. De ahí que Schelling presente al mal como un no-ente, que, sin embargo, es muy real y que no debiendo ser, sin embargo es ${ }^{54}$.

Zizek identificará de este modo lo Real (lo Real real, siguiendo su propia terminología ${ }^{55}$ ), como aquello que, según veíamos al comienzo, se opone activamente a la existencia: "lo opuesto a la existencia no es la no existencia, sino la insistencia: lo que no existe, continúa insistiendo, tendiendo a la existencia" ${ }^{56}$. Es decir, que esa "insistencia" corresponde precisamente con lo no-ente: no existe, pero es y dado que es, no es una nada. Sin embargo habría que hacer una serie de matizaciones. Pese a que Zizek se refiere explícitamente a Schelling para dar cuenta de lo Real como "insistencia", lo que él afirma en la cita que acabamos de recordar tiene dos niveles: por un lado, toda insistencia implica el ejercicio activo de una fuerza contraria, un perseverar, esto es, hacer un esfuerzo constante por alcanzar algo, no una latencia. Según Schelling "el Resto" está siempre presente, como una fuerza activa pero no activada. Si lo fuera "el mismo principio que en su operatividad nos porta y sostiene, en su operatividad nos consumiría y aniquilaría" ${ }^{57}$. El modo de ser de lo no-ente es por tanto la latencia "activa" pero no "operativa", una fuerza constituida por el modo de una retracción, en la que lo efectivo (wirklich) no es lo posible (möglich), pero donde lo posible permanece como fundamento de lo efectivo. En segundo lugar, y dado que

${ }^{52}$ WA I. $36.37 ; 61$.

${ }^{53}$ WA I $36.37 ; 62$.

${ }^{54}$ Zizek analizará esta relación del mal, lo Real, lo espectral, lo monstruoso y lo inconsciente ya en su primera gran obra: El sublime objeto de la ideología de 1989 (Siglo XXI, Madrid, 2012, pp. 218 y ss).

${ }^{55} \mathrm{Cf}$. supra n.19.

${ }^{56}$ Zizek, S.: Bienvenidos al desierto de lo real, op. cit., p. 22.

${ }^{57}$ WA I $24.25 ; 57$. 
permanece como latencia, no tiene tanto que ver con "lo que debería haber hecho y no he hecho", sino con lo que "podría suceder y no debería". Por lo dicho, toda existencia tiene que someter o contener a su fundamento, como quien con la mano tapona el orificio en un barril para contener la presión. Llevado a términos psicológicos, podría decirse que lo consciente contiene activamente a lo inconsciente, aunque lo inconsciente está funcionando en otro nivel no visible de la psique. Si lo inconsciente es "activado" entran en funcionamiento las pulsiones (el ello freudiano). Es entonces cuando la realidad del sujeto consciente (el yo) se tambalea. Lo Real es activo, oposición real, pero no es operativo: una presencia, una sombra que viene de lejos que, precisamente por su carácter inasible, genera "espectros": "la noción de lo Real que aquí se presupone-sostiene Zizek- es lo Real como-imposible en el sentido de la gran ausencia: siempre se te escapa, es un vacío fundamental y la ilusión consiste en pensar que lo vas a atrapar [...] lo Real es en realidad demasiado traumático para confrontarlo: hacerlo directamente sería una experiencia imposible, incestuosa y auto-destructiva" y, sin embargo, sostiene Zizek "el problema con lo Real es que ocurre, y esto es el trauma" 58 . Es decir, la materialización de lo no-ente, de aquello que "no debería suceder y sucede" o, según una formulación muy conocida: aquello que "debiendo permanecer oculto, sin embargo, se ha manifestado". Lo Siniestro.

Seguramente el texto más citado de Schelling sea aquel que repite Freud en su breve artículo Lo siniestro, aparecido en 1919, en el que para definir el término "siniestro" se recupera la formulación schellinguiana: "Se denomina Unheimlich todo lo que, debiendo permanecer secreto, oculto... no obstante, se ha manifestado" "59. Según esta definición lo siniestro se da en el seno de lo familiar: no algo extraño que irrumpe desde fuera, sino algo que estando oculto en lo más nuestro, pongamos por caso, nuestra realidad, aparece desde dentro y convierte lo más propio y familiar en algo extraño. Justamente como un espectro, un re-venant, "lo que regresa". Lo siniestro es así la aparición de lo que debería permanecer sometido o contenido. En este sentido Zizek afirmará que, sin duda, pueden leerse las Edades del mundo, como él mismo hace, como "un escrito metapsicológico en clave freudiana en el más estricto sentido" ${ }^{60}$. Lo Real, así pues, en el plano de la historia, tiene que ver con ese acontecimiento que nos sobrepasa, con la aparición del fantasma, que, al no poder ser asimilado por

\footnotetext{
${ }^{58}$ Zizek, S.: Arriesgar lo imposible. Conversaciones con Glyn Daly, op. cit., p. 69-70.

${ }^{59}$ Freud, S.: "Lo siniestro". En Obras completas, tomo 7, Madri, Biblioteca Nueva, 2006, p. 2487.

${ }^{60}$ Zizek, S.: The indivisible remainder. On Schelling and related matters, op. cit., p. 9. Para profundizar en esta lectura y la relación de Schelling con lo siniestro freudiano Cf. Goddard, J.-F.: "Freud et Schelling. Unheimlichkeit et refoulement". En Ferrer, P.-Pedro, T. (Eds): Schellings Philosophie der Freiheit. Studien zu den Philosophischen Untersuchung über das Wesen der menschlichen Freiheit, op. cit, pp. 277-285.
} 
la razón, se cubre con ropajes ficticios, aunque estos ropajes no hagan sino cubrir el lugar de la herida, como un paño que ocultara el vacío dejado por lo Real en el movimiento de su retirada: "el núcleo duro de lo Real que sólo somos capaces de soportar si lo convertimos en ficción" ${ }^{\prime 1}$. Piénsese por ejemplo que la reacción mayoritaria ante el atentado contra las torres gemelas era que se trataba de una película. No es baladí que Zizek presente esta interpretación de lo Real, tras el 11S, en un texto de título Bienvenidos al desierto de lo real, que constituye una explícita referencia a uno de los diálogos de la película Matrix (Wachowski, 1999) en la que el protagonista es despertado de un sueño virtual inducido por un mundo maquínico, en el que se toma por realidad una reconstrucción virtual. La realidad "real" según el argumento de la cinta ha quedado reducida a escombros, es un desierto gris e inhóspito, que algunos preferirían no haber visto jamás. Pero el problema es que lo que se muestra al protagonista no es lo real en si mismo, sino una representación, una simulación realizada con ordenador. Representación de representación. Juego de espejos.

\section{Los simulacros}

Es este juego de espejos, la virtualización casi completa de nuestro entorno (todo está mediado por los "media", por la técnica en sus diferentes modos) lo que ha llevado, según Zizek, a la experiencia de que estamos viviendo cada vez más en un universo construido artificialmente ${ }^{62}$. Y mientras que Zizek habla del deseo de "autenticidad", que lleva, por ejemplo, a la práctica del cutting (infligir cortes en el cuerpo para que, mediante el dolor, se pueda afirmar la autenticidad de la propia existencia. Piénsese, en otro nivel, en las performances de Marina Abramovic que tratan de mostrar cómo a través del dolor se accede a otros niveles de "realidad"), Baudrillard afirmará que, en realidad, la imagen que cubre transparentemente otra imagen, remite a un "refugio en lo virtual": "A la catástrofe de lo real -dirá Baudrillard-preferimos el exilio de lo virtual, cuyo espejo universal es la televisión" ${ }^{63}$. Valga decir: mundo de imágenes, televisión, internet, youtube, facebook... Vivimos en la época del simulacro, es decir, en la época de lo que se presenta como real y no lo es, de lo que no existe, y es, o mejor, es en el modo de un "no-ser" con "efectos" (Wirkung) en la realidad (Wirklichkeit).

Baudrillard comenzará "La precesión de los simulacros" con la conocida fábula de Borges según la cual los cartógrafos del imperio habían trazado un mapa que trataba

\footnotetext{
${ }^{61}$ Ibid, p. 21.

${ }^{62}$ Zizek, S.: Bienvenidos al desierto de lo real, op. cit., p. 20. Véase también el enjundioso estudio de Byung-Chul Han: La sociedad de la transparencia, Barcelona, Herder, 2013.

${ }^{63}$ Baudrillard, J.: La guerra del Golfo no ha tenido lugar, Barcelona, Anagrama, 2001, p. 16.
} 
de ser un calco perfecto del territorio a cubrir; pero hoy, como dirá Baudrillard, "la simulación no corresponde a un territorio, a una referencia, a una sustancia, sino que es la generación de los modelos de algo real sin origen ni realidad [...] En adelante será el mapa el que preceda al territorio [...] y el que lo engendre" ${ }^{\circ 4}$. Imagen sin referente. "Ya no es más que algo operativo que ni siquiera es real" ${ }^{\circ 5}$. En el plano de la historia esta inoculación de simulacros y apariencias en la realidad, tiene su impacto en la forma con la que interpretamos lo acontecido. De hecho es este carácter de simulación lo que llevó a Baudrillard a sostener que, inmersos en la cultura del espectáculo que caracteriza a nuestro tiempo, por decirlo con Debord, la guerra del Golfo "no tuvo lugar", no porque no fuera auténtica, sino porque su caracter de realidad venía dado por su carácter espe(cta)cular, "falsificar los finales y el cálculo sobre los finales, falsificar el tiempo y el acontecer de las cosas, precipitar su curso, con la impaciencia del cumplimiento, o mediante la intuición secreta de que la promesa del cumplimiento es de todos modos, ella también, falsa y diabólica" ${ }^{66}$. Acontecimientos, pues, que no siendo, tienen efectos.

\section{Segundo uso de lo no-ente en Schelling.}

Schelling afirmará que su concepto de no-ente es deudor del de Platón ${ }^{67}$, que en el Sofista ${ }^{68}$, y desoyendo los consejos de Parménides en su poema, se interrogó por la posibilidad de un tercer camino entre el ser y el no-ser o, dicho de otro modo, por cómo aquello que positivamente no es real, sin embargo es. Si lo que es, es lo verdadero -reflexiona Platón- y lo verdadero tiene como contrario lo falso, ¿qué hacemos con lo falso? ¿acaso no es? Habrá que decir, en primer lugar, que lo falso es, puesto que puede decirse y predicarse. Ahora bien, su forma de ser es diferente de lo que es verdadero: existe, puesto que participa del ser, pero "es" de forma diferente. No es su contrario, en cuyo caso simplemente no sería, sino una forma de "ser" que tiene su propia naturaleza y su propia realidad. "Entonces, como tú dices, no es para nada inferior a las otras realidades, y se debe tener el coraje de decir que el no-ser existe firmemente, y que tiene su propia naturaleza [...] el no-ser en sí [es] y es no-ser" (258 b-c). En segundo lugar, mientras que lo que es, lo verdadero, se adecúa con la

${ }^{64}$ Baudrillard, J.: "La precesión de los simulacros". En Cultura y simulacro, Barcelona, Kairós, 2008, pp. 9-10

${ }^{65}$ Ibid, p. 11.

${ }^{66}$ Baudrillard, J.: La ilusión del fin. La huelga de los acontecimientos, Barcelona, Anagrama, 2004, p. 20.

${ }^{67}$ WA I, 36.37; 61.

${ }^{68}$ Sofista, 240e-259b. 
realidad, con lo que hay, es decir, tiene un referente, no así lo falso, que aunque designa la existencia de algo, ese algo no tiene por qué adecuarse a la realidad de lo que hay, y así, en curiosa correspondencia con lo afirmado por Baudrillard sobre los simulacros, se afirma que "[...] cuando existe lo falso, existe el engaño [...] Y cuando existe el engaño, todo se llena necesariamente de imágenes, de figuras y de apariencias" (260 c).

En el Escrito sobre la libertad Schelling seguirá este planteamiento de Platón para explicar un plano diferente de lo no-ente, que tiene que ver con la efectividad de lo que no es de suyo y que asocia al problema del mal entendido no como privación, falta o defecto, sino como "un trastorno positivo o inversión de los principios"69.

Para entender esta relación entre el mal, la inversión o transtorno de los principios y lo no-ente, hay que recordar en primer lugar que el texto de 1809 , consagrado al problema del mal, retoma la idea central de la Naturphilosophie según la cual en el proceso de autorrevelación del Absoluto, la naturaleza, como consecuencia de la oposición dinámica de las fuerzas contractiva (Grund) y expansiva (Existenz), se despliega en una serie de $\operatorname{grados}^{70}$, pero si bien no se detiene a explicar el complejo desarrollo del proceso - que da por sabido porque presupone un conocimiento previo de su obra- sí explica tanto el origen del conflicto como su final. Esta explicación es necesaria, como el propio filósofo reconoce, pues qué sea el mal tiene una relación directa con el orden natural ${ }^{71}$. En el proceso de despliegue hay un equilibrio de fuerzas que es alterado cuando el mal se hace efectivo. De ahí que el bien tenga que ver con permanecer dentro del orden, y el mal con el trastorno interno del equilibrio de fuerzas. El modo de su actuación es el mismo que el de un parásito, de ahí la analogía que Schelling hace entre el mal y la enfermedad, no porque el mal sea una enfermedad del absoluto, sino por su caracter de no-ente: "De igual modo que la enfermedad ciertamente no es nada en esencia, sino en realidad sólo un simulacro [o "apariencia", Scheinbild] de vida y una manera aparición meteórica [...] y no por ello sin embargo deja de anunciársele al sentimiento en menor medida como algo muy real, así sucede con el mal" 72 . Es importante aquí el término simulacro o apariencia (Scheinbild) porque el mal sería aquella imagen (Bild) falsa que se presenta como algo verdadero y activo con una existencia propia. Pero la enfermedad, como el mal, necesita de un huesped y de una red de fuerzas para alcanzar una forma de efectividad, no se trata, pues, de una carencia de salud sino de un desequilibrio de las fuerzas internas que

\footnotetext{
${ }^{69} \mathrm{SW} \mathrm{I} / 7,366 ; 185$.

${ }^{70} \mathrm{Cf}$. SW I/7, 362-364; 175-179.

71 “[...] sólo a partir de los principios de una verdadera filosofía de la naturaleza se puede desarrollar esa concepción que satisface por completo la tarea que aquí nos ocupa”. SW I/7, 357, 161.

${ }^{72} \mathrm{SW}$ I/7, 366; 185.
} 
materialmente es el mismo que en el cuerpo sano (son las mismas fuerzas), pero formalmente diferentes (su funcionamiento es diferente) ${ }^{73}$. El mal como tal puede entenderse como un no-ente: porque no es, pero tiene, sin embargo una efectividad y, por ello se manifiesta en la naturaleza a través de sus efectos ${ }^{74}$ : "el mal no es en efecto otra cosa que lo relativamente no-ente [Nichseyende], que se presenta como ente [Seyende], y suplanta por tanto a lo verdaderamente ente"75. El simulacro sería una forma de no-ser, puesto que se trata de una suplantación de lo que es sin referente previo, que alcanza una forma de efectividad y que, por tanto, tiene unos efectos en la realidad.

De forma que, volviendo de nuevo a Baudrillard, podríamos aplicar este concepto de lo "no-ente" al simulacro: aquello que ni puede ser calificado como "ente" (por no tener una realidad de suyo) ni como nada (por causar unos efectos), sino que, como un virus o como elemento parasitario, para ser efectivo necesita de la realidad de lo ente. La palabra clave aquí es "suplantación" de lo real: el simulacro aparece como aquello que es, pero que no se refiere a nada, es decir, a un acontecimiento ficticio que se toma por verdadero y que, para hacerlo, emplea los medios de lo verdadero y adopta materialmente sus formas. De nuevo Baudrillard: "No se trata ya de imitación ni de reiteración, incluso ni de parodia, sino de una suplantación de lo real por los signos de lo real, es decir, de una operación de disuasión de todo proceso real por su doble operativo, máquina de índole reproductiva, programática, impecable, que ofrece todos los signos de lo real y, en cortocircuito, todas sus peripecias" ${ }^{\text {"76 }}$. Escritura de lo irreal con los signos de lo real. Inoculaciones. Remedando al propio Baudrillard, se podría afirmar que "pasa un poco como la procreación in vitro: se transforma el embrión de noacontecimiento en el interior del útero real de la historia”. Así el acontecimiento ficticio toma cuerpo y se hace efectivo al insertarse en el tejido histórico que le proporciona materialmente las condiciones de posibilidad para su "realidad".

Por lo que hemos visto, el concepto de lo "no-ente" puede ser aplicado como pieza clave para la elaboración de una "lógica del fantasma", como dice Derrida ${ }^{77}$, que trate

\footnotetext{
${ }^{73}$ Para profundizar en esta relación remito al lector a Moiso, F.: Vita natura libertà. Schelling (1795-1809), Milán, Mursia 1990; también mi estudio "Ens alienum. El mal visto desde la Naturphilosophie en F.W.J.Schelling" en donde se profundiza la relación entre el mal y la enfermedad y la influencia en y sobre Schelling de las teorías médicas imperantes en su época. En Silvia del Lujan Di Sanza y Diana María López: El vuelo del búho. Estudios sobre filosofía del idealismo, Buenos Aires, Editorial Prometeo Libros.

${ }^{74} \mathrm{SW} \mathrm{I} / 7,377 ; 209$.

${ }^{75} \mathrm{SW} \mathrm{I} / 7,459$.

${ }^{76}$ Baudrillard, J.: "La precesión de los simulacros". En Cultura y simulacro, op. cit., p. 11. Cursiva nuestra.

${ }^{77}$ El término es empleado por Derrida en Espectros de Marx. El estado de la deuda, el trabajo del duelo y la nueva internacional, Madrid, Trotta, 1995, p. 77.
} 
de ir más allá de una lógica binaria o dialéctica y nos permita otro modo de comprensión de la historia, en la que se distinga entre diferentes modos de efectividad (presente, actual, empírica, viva) y que nos sirva para analizar los diferentes acontecimientos y no-acontecimientos de nuestra realidad, en una época, la nuestra, en la que prima lo "sintético", lo "protético" y lo "virtual" en el orden científico y lo "tecnomediático" y lo "espectacular" en el ámbito social y político, para conformar el tejido artificialmente articulado de nuestra realidad histórica.

\section{Ana Carrasco-Conde}

Doctora Europea en Filosofía, Universidad Complutense de Madrid / Universidad Politécnica de Madrid, CEI Campus Moncloa

Campus Moncloa

anacconde@ucm.es 